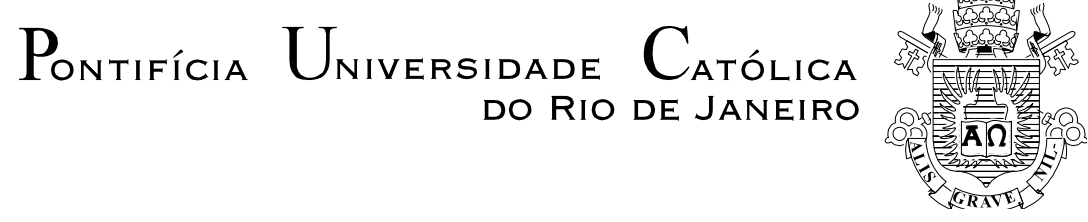

Priscila Danni Ferreira Correia

Fios de memória, redes de afetos e pontos de interseção: uma experiência teatral autorreflexiva

Dissertação de Mestrado

Dissertação apresentada ao Programa de Pósgraduação em Letras da PUC-Rio como requisito parcial para obtenção do título de Mestre em Letras.

Orientadora: Profa. Daniela Gianna Claudia Beccaccia Versiani 


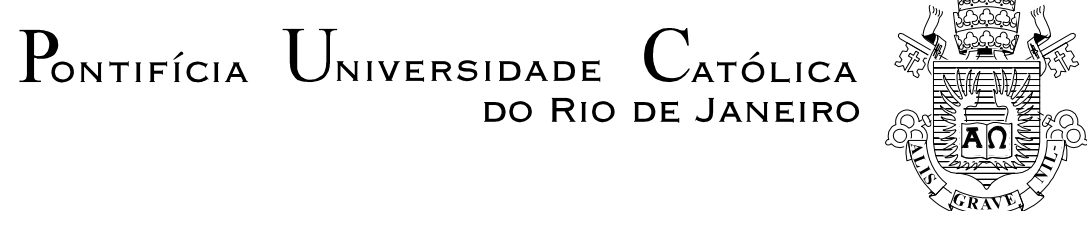

Priscila Danni Ferreira Correia

\title{
FIOS DE MEMÓRIA, REDES DE AFETOS E PONTOS DE INTERSEÇÃO: UMA EXPERIÊNCIA TEATRAL AUTORREFLEXIVA
}

\author{
Dissertação apresentada como requisito \\ parcial para obtenção do grau de Mestre pelo \\ programa de Pós-Graduação em Letras do \\ Departamento de Letras do Centro de \\ Teologia e Ciências Humanas da PUC-Rio. \\ Aprovada pela Comissão Examinadora abaixo \\ assinada.
}

Profa. Daniela Gianna Claudia Beccaccia Versiani Orientadora Departamento de Letras - PUC-Rio

Profa. Marília Rothier Cardoso Departamento de Letras - PUC-Rio

Profa. Tatiana da Motta Lima Ramos UNIRIO

Profa. Denise Berruezo Portinari Coordenadora Setorial do Centro de Teologia

e Ciências Humanas - PUC-Rio

Rio de Janeiro, 07 de abril de 2011 
Todos os direitos reservados. É proibida a reprodução total ou parcial do trabalho sem autorização da universidade, da autora e do orientador.

\section{Priscila Danni Ferreira Correia}

Iniciou carreira artística em 1994 e apresentou-se em diversos espetáculos profissionais. Formou-se em Letras na Universidade Estácio de Sá em 2006. Participou de workshops e seminários em Teatro e apresentou trabalhos de pesquisa em congressos na área de Letras, sobre produção de conhecimento em teatro. Fundou, com mais sete artistas, a Cia. VIDA de Teatro e Dança (Maricá/RJ) - Ponto de Cultura do Estado do RJ, onde trabalha como arte educadora. Criou, com Bruno Henríquez, o grupo de pesquisa e experimentação cênica Teatro METAPHORA. Integrou o grupo OMAME Teatro, sob direção de Marilenna Bibas, por dois anos, e após residência artística na Fundación Teatro Varasanta (Colômbia), dedica-se às pesquisas sobre treinamento e preparação de atores.

Ficha Catalográfica

CORREIA, Priscila Danni Ferreira.

Fios de Memória, Redes de Afeto e Pontos de Interseção: uma experiência teatral autorreflexiva / Priscila Danni Ferreira Correia; orientador: Daniela Gianna Claudia Beccaccia Versiani - Rio de Janeiro: PUC, Departamento de Letras, 2011.

v., 84 f.: il. ; $30 \mathrm{~cm}$

1. Dissertação (mestrado) - Pontifícia Universidade Católica do Rio de Janeiro, Departamento de Letras.

Inclui referências bibliográficas.

1. Letras - Teses. 2. Ator-pesquisador. 3. Investigação de processos cênicos. 4. Teatro de pesquisa/Terceiro teatro. 5. Escrita autorreflexiva. I. Correia, Priscila D. F. (Priscila Danni). II Pontifícia Universidade Católica do Rio de Janeiro. Departamento de Informática. III. Título. 
Para os meus pais, Marilia Danny e Paulo Ernani, o afeto primeiro e maior de todas as coisas, ...e meu irmão, Lucas Danny, para que, na busca de seus caminhos, lembre-se que "A verdade está no meio". 


\section{AGRADECIMENTOS}

A Deus, sobretudo, força suprema, que nós dá o impulso, o fluxo e o movimento.

A minha mãe, mestra. Ventre e colo quentes, mãos firmes e acolhedoras. Fortaleza e suavidade. Lágrimas contagiantes e o dom de viver a vida e a arte, entre panos de chão, sorrisos, panelas e movimentos encantadores. Rainha, atriz, bailarina e poeta do olhar. Amizade e amor maior da minha vida.

A Daniela Beccaccia Versiani, orientadora no sentido mais genuíno da palavra, amiga, irmã, mãe, tia, carinho, coração e bússola: por TUDO, simplesmente.

Às professoras Marilia Rothier Cardoso e Heidrun Olinto, pela co-orientação, disponibilidade, atenção e apresentações teóricas fundamentais.

À professora Tatiana Motta Lima, por todo o carinho, incentivo, estudos, partilhamentos e oportunidades.

Ao CNPq e à PUC-Rio, pelos auxílios concedidos.

Aos meus companheiros Bruno Henríquez e Roberta Dittz, inspiração e expiração, impulso nervoso e fluxo criativo. Irmãos. Caminho. O sentido mesmo da palavra destino.

À Marilenna Bibas, pela paciência nos ensinamentos primordiais.

Ao meu mestre Fernando Montes e os amados companheiros do Teatro Varasanta: Chava, Beto, Lili, Marcita, Pacho, Gina e Vero, pelo ENCONTRO, ponte e passagem na construção do conhecimento, compreensão de nosso ofício e amor pela humanidade.

Aos amigos artistas de Kilele: Catalina Medina, Nelson Camayo, Eduardo Guevara, Magda Niño, Elizabeth Ramirez e Nicholas Cancino, pelas conversas, histórias e depoimentos de uma trajetória rio adentro. 
Ao grupo TEATRO METAPHORA. Entidade, fé, comunhão, reconstrução do "in-diví-duo", busca para além de NÓS.

A Eugène Ionesco - gênio amigo, ranzinza, paquiderme de seu tempo, vulcão pelas conversas, risos e reflexões.

À Armazém Companhia de Teatro, grupo, força e fonte de pesquisa. Em especial à Patrícia Selonk, fonte de inspirAÇÃO.

A Constantin Stanislavki, Eugenio Barba, Jerzy Grotowski, Hans-Ulrich Gumbrecht e Gilles Deleuze, por pacientemente suturararem minhas feridas.

À Kaka, que cuida de mim.

À Nina Simone e Mercedes Sosa, que também cuidam de mim.

A minha família de vida, de arte, de pesquisa: Ingrid Oliveira, Marcus Faro, Hugo Grativol, Diego Riques, Ayumi Souza, Raphaela Tafuri, Jean Cândido Brasileiro, Karen Brustolin, Angele Delieux, Gabriel Velasco, Alisson Jardel, Carol Feitosa, Patt Carvalho, Ederson Porto, Bella Carvalho, Ulli Castro, Jan Andrade, Victor David, Manuela Freire, Malu Travassos, Leonel Henckes, Rafael Dellamora, Pablo Aguilar, Gabriela Estevao, Débora de Magalhães, Rosi Trindade, Dan, Aninha e Leo, Fernanda, Mariana, Nescau, Felipe, Ticinha, Tia Rosa, Tia Nilce, Dinda, Naná, Victor, minhas velhas, Jay, Gui, Tia Marlene e tio Paulo, Kika e Paulão, todas as tias, Kovak, Vegita, Smirnoff (em memória), Janis Joplin, Beatles, Ella Fitzgerald, Oswaldo Montenegro, Elis Regina, Los Hermanos, Madeleine Peyroux, Edith Piaf, Fernando Pessoa, Clarice Lispector, Jorge Luis Borges, Virgínia Woolf, Dave Eggers, Mario de Sá-Carneiro, Anton Tchekhov, Bertold Brecht, Shakespeare, Pablo Neruda, Florbela Espanca, Johannes Vermeer, Jack Vetriano, Livraria da Travessa.

À Flávio Serra e meu avô, na espiritualidade. 


\section{Resumo}

Correia, Priscila Danni Ferreira; Versiani, Daniela Gianna Claudia Beccaccia. Fios de memória, redes de afeto e pontos de interseção: uma experiência teatral autorreflexiva. Rio de Janeiro, 2011. 84p. Dissertação de Mestrado Departamento de Letras, Pontifícia Universidade Católica do Rio de Janeiro.

Este trabalho se insere em uma vasta rede de construção de conhecimento que envolve atualmente múltiplos conceitos teóricos de diferentes áreas do saber. Nesta dissertação, optou-se por estabelecer uma rede conceitual baseada em artistas/teóricos como Constantin Stanislaski, Jerzy, Grotowski, Eugenio Barba e Hans-Ulrich Gumbrecht, para dialogar com uma experiência teatral particular. É um experimento autorreflexivo de uma atriz-pesquisadora que propõe lançar à página a metodologia desenvolvida em sua prática teatral, tecendo fios de memória e redes de afetos, com o intuito de acentuar pontos de interseção entre teoria e prática, ação e reflexão, corpo e palavra. Desenvolve-se na escrita um jogo de encenação, dialógico, que tem como elementos constituintes: autores, palavras-chave, metáforas e citações. A utilização específica desse conjunto de elementos interposto em relação à memória afetiva da atriz é o ensaio de uma metodologia alternativa para a escrita acadêmica.

\section{Palavras-chave}

Ator-pesquisador; investigação de processos cênicos; teatro de pesquisa/ terceiro teatro; escrita autorreflexiva. 


\section{Resumen}

Correia, Priscila Danni Ferreira; Versiani, Daniela Gianna Claudia Beccaccia (orientadora). Hilos de memoria, redes de afecto y puntos de intersección: una experiencia teatral auto-reflexionada. Rio de Janeiro, 2011. 84p. Tesis de Maestría - Departamento de Letras, Pontifícia Universidade Católica do Rio de Janeiro.

El presente trabajo se inserta en una vasta red de construcción del conocimiento que implica múltiples conceptos teóricos de diferentes disciplinas. En esta tesis, se decidió establecer una red conceptual que incluye artistas y teóricos como Constantin Stanislaski, Jerzy Grotowski, Eugenio Barba y Hans-Ulrich Gumbrecht, para hablar con una experiencia teatral en particular. Es un experimento auto-reflexivo de una actriz-investigador que propone poner en la página la metodología desarrollada en su práctica teatral, tejiendo hilos de memoria e redes de afectos, con el fin de encontrar puntos de intersección entre la teoría y la práctica, la acción y la reflexión, la palabra y el cuerpo. Desarrollase en la escritura un juego de puesta en escena, dialógico, cuyos elementos constitutivos son autores, palabras clave, metáforas y citas. El uso específico de este conjunto de elementos interpuesto en relación con la memoria afectiva de la actriz está poniendo a prueba una metodología alternativa a la escritura académica.

\section{Palabras clave}

El actor-investigador; la investigación de los procesos escénicos; teatro de investigación/ tercero teatro; la escritura auto-reflexionada. 
Sumário

1. Prólogo 11

2. Introdução 12

3. Linguagem

I 19

II 21

III $\quad 24$

IV 30

V 33

$\begin{array}{ll}\text { VI } & 37\end{array}$

$\begin{array}{ll}\text { VII } & 38\end{array}$

4. Processo 41

VIII $\quad 42$

$\begin{array}{ll}\text { IX } & 47\end{array}$

$\begin{array}{ll}X & 49\end{array}$

XI 56

5. Ação 60

XII 61

XIII $\quad 64$

$\begin{array}{ll}\text { XIV } & 67\end{array}$

$\begin{array}{ll}X V & 70\end{array}$

$\begin{array}{ll}X V I & 73\end{array}$

$\begin{array}{ll}X V I I & 75\end{array}$

$\begin{array}{ll}X V I I I & 76\end{array}$

$\begin{array}{lr}X I X & 80\end{array}$

6. Referências Bibliográficas 83 
Eu não sou eu, nem sou o outro Sou qualquer coisa de intermédio

Pilar da ponte de tédio Que vai de mim para o outro

Mário de Sá-Carneiro 